\title{
Adoption Data and Statistical Trends
}

FRANK $B I A F O R A$

DAWN ESPOSITO

\author{
St. John's University
}

\section{SOURCES OF ADOPTION DATA}

There has never been a single, comprehensive, and continuous national data collection effort to capture information on all adoption activity in the 50 states of the United States and its territories. For the most part, what we know of the extent of formal adoption practices, whether public or private, domestic or international, derives from a combination of disparate data sources often pieced together and often estimated. The lack of a complete and consistent database is not surprising, argues Pertman (2000), considering that

generations of secrecy have prevented us from knowing just how widespread [adoption] has become. The subject has been considered off-limits for so long, both by individuals and by society as a whole ... that determining how many triad members there are-or have been-would require sorting through the individual finalization records of every courthouse in every city and town in every state. (pp. 8-9)

Adoption data that are available vary in terms of purpose, reliability, and length of recording. The most common sources of adoption statistics today include (1) state court records of adoption filings and dispositions, (2) national foster care records compiled from state public welfare divisions, (3) U.S. State Department records of issued international visas, (4) vital records of birth certificates, and (5) general population surveys, including the U.S. Census. The first three of these capture information related to formally recognized adoptions, whereas population surveys remain the primary sources for providing information on the extent of informal caregiving, adoption demand, and adoption-seeking behaviors. State bureaus of vital records have also been an important resource in keeping track of reissued birth certificates.

Each of these data sources, coupled with recent advances in electronic data-gathering technologies, has made numerical compilation of adoption activity more possible than 
ever before. The best estimates today suggest that about 125,000 adoptions occur each year (U.S. Department of Health and Human Services, 2004), that $2 \%$ of all children residing in the United States are adopted, and that as many as $4 \%$ of all families in the United States have an officially recognized adopted child (Child Welfare League of America [CWLA], 2005). Moreover, when these formal counts are coupled with statistical estimates of undocumented kinship care and informal adoption, some researchers suggest that as many as $7 \%$ of all children in the United States currently reside in some form of substitute/adoptive relationship (Testa \& Falconnier, 1998). Most recent estimates from the U.S. Census put the total numbers of adopted children under the age of 18 at 1.6 million (Kreider, 2003), with as many as 6 million adoptees of all ages residing in the United States (Pertman, 2000).

While some success has been made in the area of data collection and dissemination, there is still much room for improvement. What might be considered a recent success in this area can be traced to three, if not more, sources, among which are federal adoption legislation and mandates, a growing awareness as a function of adoption institutes and national organizations, and an expanding interest in adoption by academic institutions and legal scholars. Additionally, the U.S. Department of Health and Human Services, Administration for Children and Families, has carved out funding for the National Adoption Information Clearinghouse (NAIC). The NAIC serves professionals, policymakers, and citizens by synthesizing data and providing information on adoption research and statistics. However, there is some concern that these recent investments in data gathering and reporting may be short-lived because of mounting federal and state budget deficits (McFarland, 2003). In times of budget downturns, many of the agencies currently responsible for data gathering may find it difficult to continue to collect and maintain critical data on the characteristics of adoption.

\section{Limited Private Adoption Data}

Throughout the past 60 years, various divisions and offices within the federal government have played an important role in capturing basic statistical information on national adoption activity, with most success coming in the form of tracking public agency and international adoptions. Very little progress has been made by federal authorities in capturing consistent and reliable data on the extent of formal adoptions processed privately or independently through adoption mediators. This latter point is particularly significant when one considers that until only recently (i.e., about the time states were to receive financial incentives for adoption placements - see the section describing the Adoption and Foster Care Analysis and Reporting System [AFCARS] below) the number of private adoptions have far outpaced the number of public welfare adoptions (Flango \& Flango, 1995). It is through private adoption agencies that a majority of healthy infants and children are placed. The general lack of voluntary cooperation by private adoption agencies to engage in statistical reporting is not surprising for two reasons. The first relates to the fact that there are no incentives (or punishments) for private agencies to report information to outside sources (McFarland, 2003). A second reason is more a comedy of errors, suggests a report by the U.S. Department of Health and Human Services (2004), in that "some private agencies assume that these data are already captured by public agencies, who in turn are often under the impression that private agencies keep comprehensive information on their own adoptions" (p. 16). As is commonly found throughout the adoption literature as well as with the data trends (including those presented in this chapter), data analysts have, out of necessity, "backed out" the counts of private agency adoptions by subtracting from state court reports the numbers of completed public adoptions and international adoptions, thereby leaving estimates of remaining private, kinship, and tribal adoption activity (U.S. Department of Health and Human Services, 2004).

National Center for Social Statistics (NCSS)

Annually between 1957 and 1975, the federal government worked with state-run agencies on a voluntary basis to capture basic summary information on finalized adoptions using data 
primarily from state court records (Maza, 1984; Stolley, 1993). Coordinated by the Children's Bureau and the National Center for Social Statistics (NCSS), adoption cases, both public and private, were collected and compiled, offering legislators and human services personnel for the first time longitudinal estimates of national adoption trends. Early in this process, less than one half the states participated in the annual survey. By 1966, all 50 states participated in the NCSS data-gathering effort. A summary report published by the Administration for Children, Youth and Families (Maza, 1984) remains one of the most widely referenced, estimating that the total numbers of domestic adoptions doubled from about 50,000 in 1944 to 100,000 by 1950, reaching a peak of about 175,000 by 1970 (see Figure 3.1).

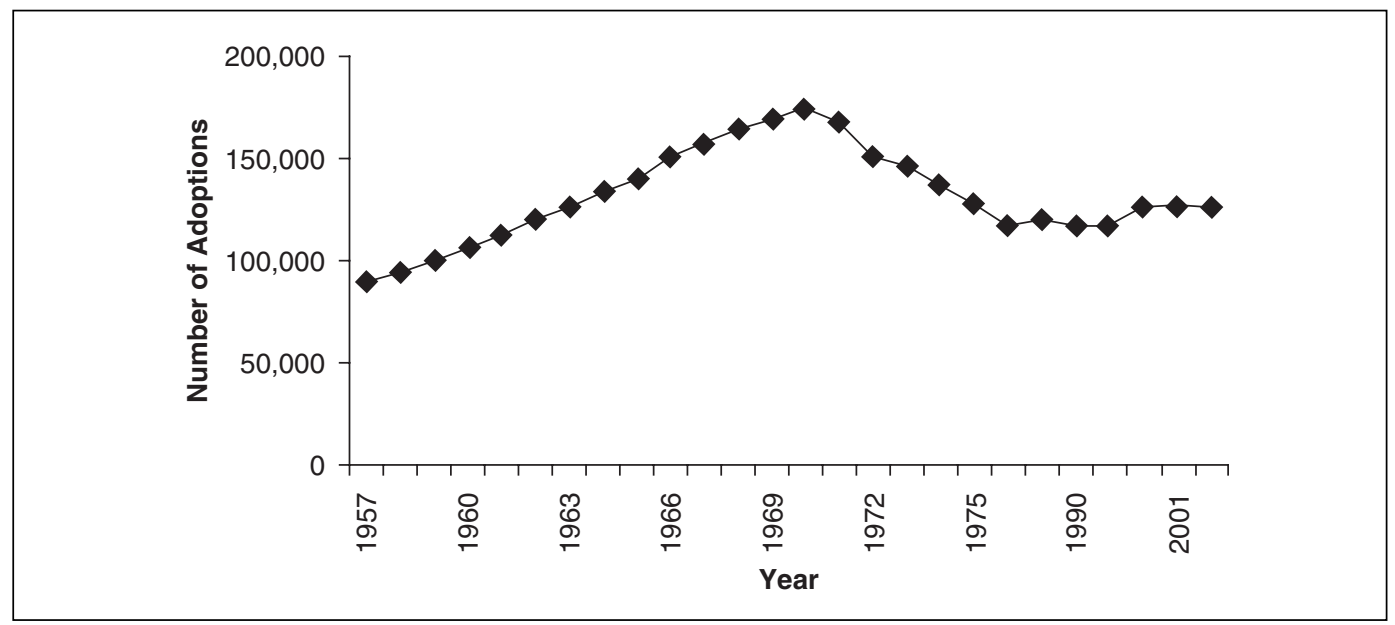

Figure 3.1 Estimated Number of Total Adoptions (1957-2001)

SOURCES: The 1957 to 1975 estimates are from National Center for Social Statistics reports (Maza, 1984); the 1987 to 1992 estimates are from Voluntary Cooperative Information System reports (Flango \& Flango, 1995); and the 2000 to 2001 estimates are from National Center for State Courts (U.S. Department of Health and Human Services, 2004).

\section{NCSC, AFCARS, and International Visas}

When the NCSS was dissolved in 1975, with it went any serious effort for several years to secure national adoption information on a systematic basis. Despite further limited attempts by the federal government to track national adoption trends through special project grants and a voluntary reporting survey, commonly known as the VCIS (Voluntary Cooperative Information System), administered for a brief time by the American Public Welfare Association (see Stolley, 1993), those interested in monitoring adoption trends would have to wait several years before reliable data would again became available from two important but unrelated sources: (1) the not-for-profit National Center for State Courts (NCSC-not to be confused with the NCSS) Adoption Technical Assistance Project, and (2) the national Adoption and Foster Care Analysis and Reporting System (AFCARS). Both the NCSC and the AFCARS have since become the authoritative resources for general adoption statistics.

The NCSC has collected and compiled data on the total number of public and private adoptions processed through the courts by calendar year since 1987 (Flango, 1990; Flango \& Flango, 1995). The NCSC organized in 1971 at the request of then chief justice Warren Burger, who argued for the creation of a central information and technical clearinghouse that could serve state court representatives (see www.ncsconline.org). Because adoption is a process that requires court action, the NCSC was in a good position to develop a recording protocol, making it possible for state courts to systematically report out on basic adoption 
activity, regardless of whether the adoption had originated through a private or public agency. Two central pieces of information have customarily been obtained and reported by the NCSC project-counts of adoption petitions filed with the courts and the number of cases disposed. Unfortunately, no other detailed information is captured at this time. As such, the NCSC is unable to discern the race, age, gender, or special needs of the adopted person or any relevant information regarding the birth or adoptive parents. While the filed court records may in fact capture these data, currently there exists no systematic datagathering effort by the NCSC to extract them. Despite these limitations, the courts remain perhaps the single best source for total numbers of adoptions in the states.

AFCARS emerged originally under the 1986 federal mandate (Title IV-E, Section 479 of the Social Security Act, as amended by Pub. L. No. 99-509, Section 9443 of the Omnibus Budget Reconciliation Act) and was later enhanced as part of the 1997 Adoption Incentive Program (also known as the Adoption Bonus Program) under Pub. L. No. 105-89, the Adoption and Safe Families Act (ASFA) (Maza, 2000; U.S. Department of Health and Human Services, 2004). AFCARS represents the intersection of several major trends in federal and state child welfare programming, namely, outcome-based accountability and the shift toward "early permanency" over "family reunification" as part of the "best interest of the child" philosophy (Maza, 2000, p. 445). Under the direction of President Clinton in 1996, the secretary of the U.S. Department of Health and Human Services was charged with developing and implementing a strategy that would achieve permanency more quickly for children in out-of-home care and have as its specific target a doubling in the number of adoptions, from 27,000 to 54,000 annually. All this came together under ASFA, which established Section 473A of the Social Security Act. As part of this federal directive, Congress authorized a financial rewarding mechanism to states to be eligible to receive an annual "bonus" of up to $\$ 4,000$ for each adoption finalized, with an additional $\$ 2,000$ for special needs adoptions (Title IV-E, Adoption Assistance agreement), over an established baseline number (see U.S. House of Representatives, 2004, for the most recent explanation of the financial award structure and baseline methodology). This legislation authorized the AFCARS as the sole electronic platform for capturing case-specific public adoption data and for determining state incentive funds. AFCARS is also the only database that currently collects summary data on the characteristics of all triad members. The reporting of other adoptions such as those through independent or private agencies is only encouraged but not required. Failure to report AFCARS data or failure to report data that meets with quality check standards results in financial penalties to the states (Maza, 2000).

Last, the U.S. State Department's Office of Children's Issues and the Office of Immigration Statistics within the Office of Homeland Security records and publishes data on the number of international visas issued to immigrant orphan children adopted from abroad (U.S. Department of State, 2005). Inasmuch as the adoption takes place outside of the United States, the visa becomes the principal document for federal/state documentation and statistical recording. States are not required to document or keep data on intercountry adoptions. Although many new parents may, for added protection, "readopt" in state courts once on U.S. soil, such action is not required. Up-to-date international adoption figures and highlights can be found on the State Department's homepage (http://travel.state.gov/family).

\section{Population Surveys}

Before concluding this section, it is important to make mention of a supplemental source of data that has become increasingly important for discerning the current state of adoption practices and attitudes, namely local/state and national population-based surveys. One of the most ambitious and largest remains the National Survey of Family Growth (NSFG), a periodic survey of diverse women aged 15 to 44 designed to provide national information related to fertility, family formation attitudes, and direct measures of adoption demand and adoption-seeking behaviors (Testa \& Falconnier, 1998). Other national surveys such as the Current Population Survey (CPS) and the Survey of Income and Program Participation 
(SIPP) of the U.S. Census Bureau along with the National Health Interview Survey (NHIS) and the National Vital Statistics System (NVSS) of the National Center for Health Statistics provide additional statistical information regarding related population parameters. Periodically, not-for-profit organizations and institutes such as the Evan B. Donaldson Institute or the Dave Thomas Institute sponsor a focused study of adoption. The U.S. Census remains yet another source of important information. Questions recently added to this decennial household survey provide population estimates of the prevalence of children living in nonparent, kinship care arrangements as well as foster care arrangements.

\section{STATISTICAL TRENDS AND HIGHLIGHTS}

\section{Domestic Adoption}

What follows is a discussion of selected adoption statistics drawn from existing sources that provide a general overview of adoption trends, both nationally and internationally. It is important to remember that the data are limited and are only as valid as the primary sources discussed above. It is also important to recognize that in practice, adoption is both a formal and an informal process. Missing from the following counts are the numbers of children placed into informal arrangements involving networks of real and fictive kin. We know from previous research that the prevalence of informal caregiving by a family member, often by grandparents, is not uncommon and is highest within the African American community (Hill, 1977). We can expect kinship care to become a more popular alternative and "formalized" in the near future (Lenzini \& Russo, 2004). Some states have already begun programs of legal guardianship to complement the permanency movement. Such programs, for the first time, offer financial incentives/stipends to relatives, for example, grandparents, and other caregivers for assuming permanent child care responsibilities (Lenzini \& Russo, 2004). In three demonstration states that obtained a federal waiver (Maryland, California, and Illinois), several thousand children were rapidly moved from state custody to legal guardianship in the first 2 years of the projects.

Figure 3.1 (see page 34 ) presents the best available estimates of formally recognized adoptions in the United States over last 50 years. The data have been extracted and integrated from three sources: the NCSS for 1957 to 1975, the VCIS for 1987 to 1992, and the NCSC for 2000 to 2001. Readers are encouraged to refer to the source documents for a more detailed discussion of the research methodology and findings.

As demonstrated in the line graph, adoption grew in popularity as a form of family creation throughout the latter part of the 1950s and the 1960s, with annual legal adoptions nearly doubling in number from 91,000 in 1957 to more than 175,000 in 1970. A gradual downturn began around 1971 through 1975, the last year of continuous national data collection before the dissolution of the NCSS. Picked up again by the VCIS and later the NCSC, estimates of adoption activity have remained rather steady at around 125,000 per year through the 1980s and 1990s.

The NAIC recently published a summary document offering one of the most thorough accounts and comparisons of state-by-state adoption activity for 2000 and 2001 (U.S. Department of Health and Human Services, 2004). Selecting the "best" source of data from among court records, bureaus of vital records, and special state studies, the authors of this report present the number of recognized adoptions in the order of state population size, from the most populated (California) to the least (Wyoming). As shown in Figure 3.2, there is a general continuity between state population size and finalized adoptions.

When arranged in this fashion, we see that the adoption activity in some states is higher or lower than expected based on the population size alone. The authors of this report were unable to discern why some states, such as New York, Michigan, Maryland, Colorado, Oregon, and Kansas, had more adoptions than expected, whereas Texas and Pennsylvania had fewer. 


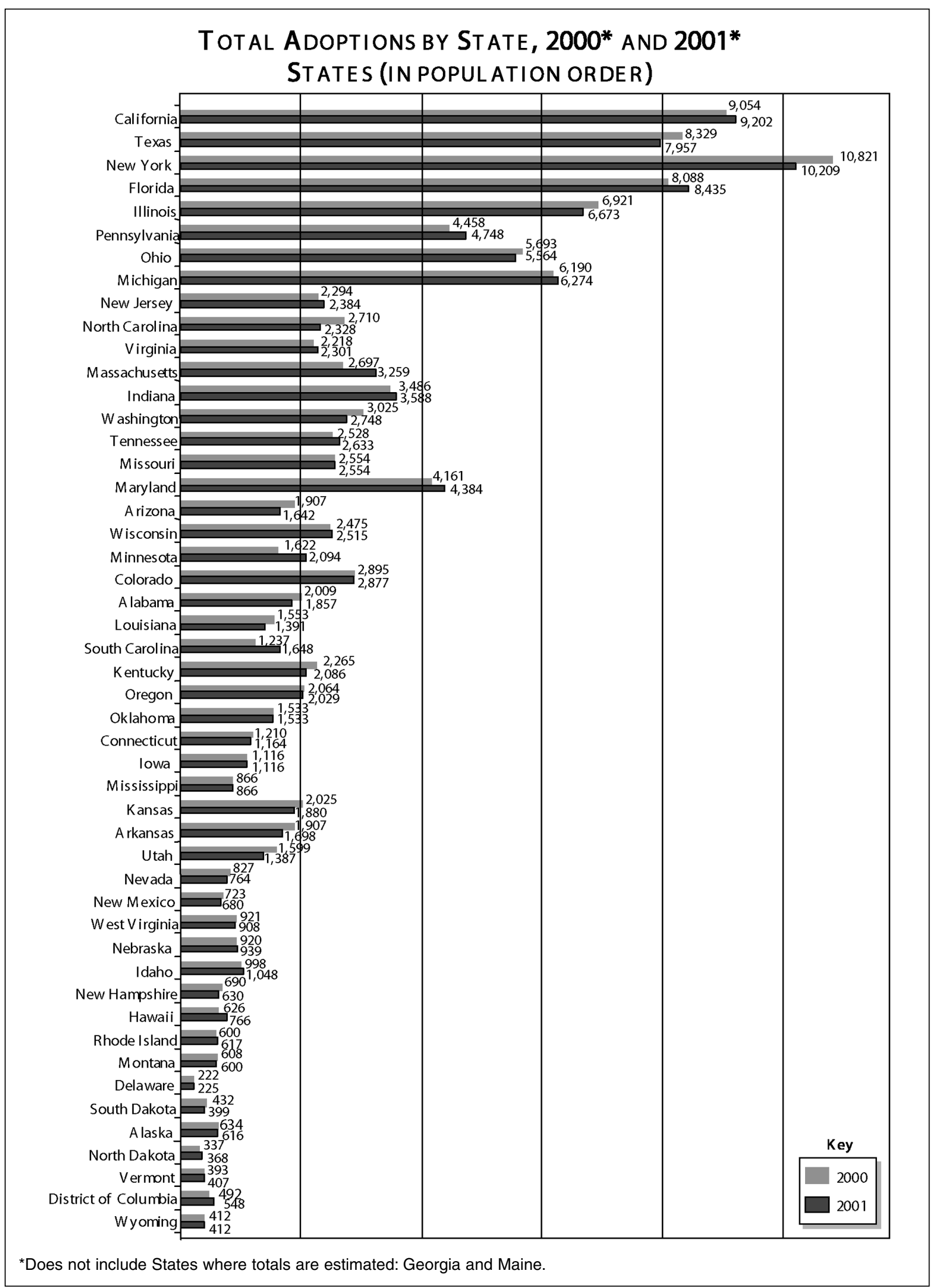

Figure 3.2 Total Adoptions by State (2000 and 2001)

SOURCE: Re-created from U.S. Department of Health and Human Services (2004). 


\section{Sources of Adoption}

After the total number of adoptions, one of the most commonly asked questions relates to the auspices of adoption placement. For decades, the prevalence of adoptions from public foster care has lagged far behind private/independent adoptions (U.S. Department of Health and Human Services, 2004). More recent evidence demonstrates the beginning of a trend whereby private domestic adoptions have become comparatively less common. Figure 3.3 offers a snapshot of adoption activity at two points in time, 1992 and 2001. Included in these data compiled and published by the National Clearinghouse are the estimated percentages of the three most common sources of adoption-public, private, and international (U.S. Department of Health and Human Services, 2004).

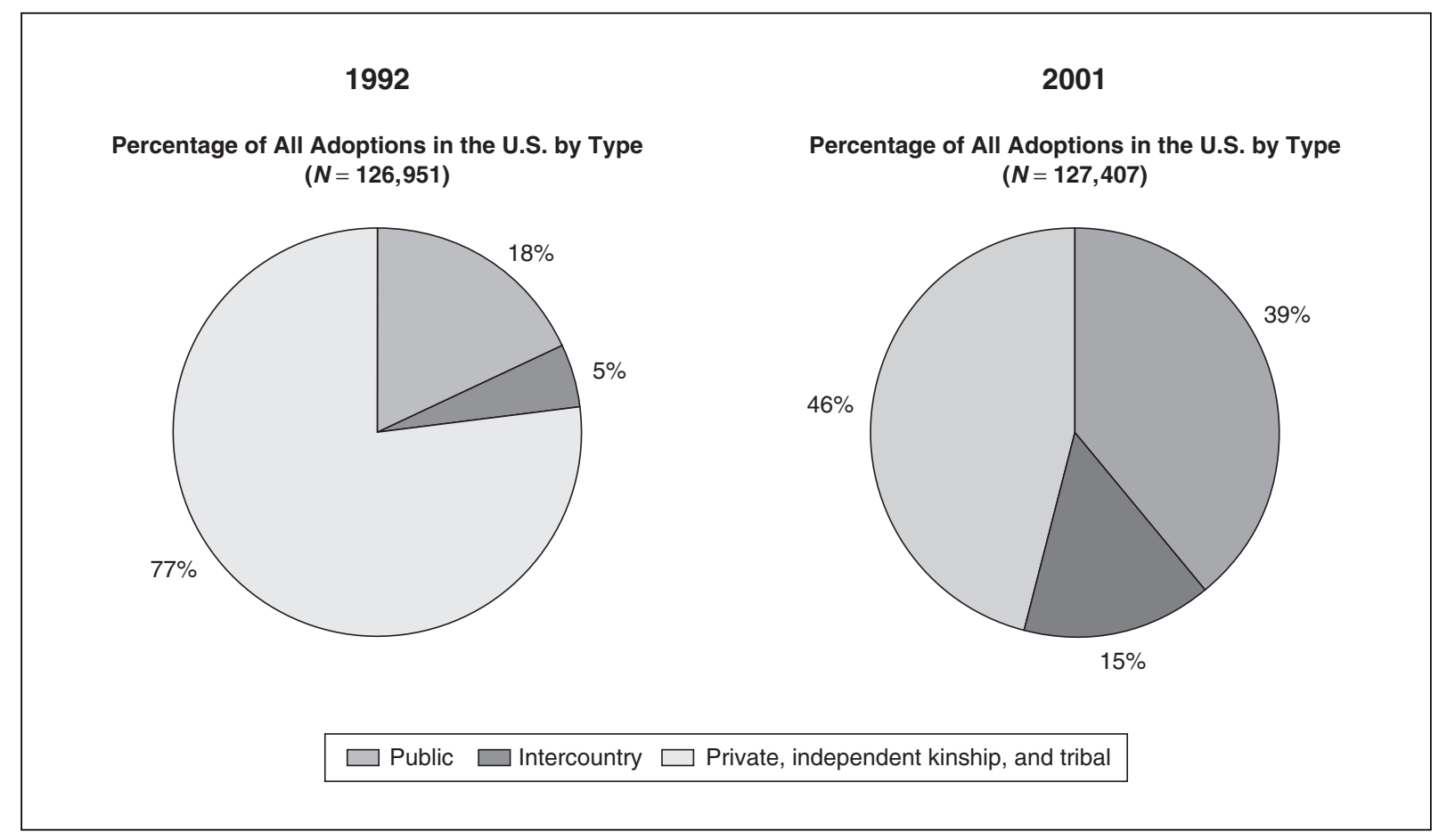

Figure 3.3 Percentage of All Adoptions in the United States by Type

SOURCE: Re-created from U.S. Department of Health and Human Services (2004).

Each of these years saw approximately the same number of recorded adoptions at about 127,000 , a figure that has remained relatively constant since the mid-1970s. In 1992, adoptions originating from private/independent sources accounted for more than three quarters of all adoptions compared with only $18 \%$ from public and $5 \%$ from international sources. In 2001, the prevalence of private/independent adoptions dropped in proportion to the others, accounting for less than one half of all adoptions, whereas public adoptions grew to account for nearly $40 \%$, a relative increase of about $117 \%$ from the previous decade. Intercountry adoptions also grew in popularity, as shown by these data, increasing from $5 \%$ to $15 \%$ of all adoptions.

It should be noted again that these statistical trends are based on national estimates and that the prevalence of public agency adoptions as a percentage of total adoptions varies considerably by state. As an example of interstate disparity, public adoption accounted for about $82 \%$ of adoptions in Illinois (67\% in Iowa and $66 \%$ in Oklahoma) in 2000, whereas 
only $10 \%$ of all adoptions in Alabama were from a public source $(13 \%$ in Wyoming and $16 \%$ in Tennessee) (U.S. Department of Health and Human Services, 2004).

It has been suggested that recent increases in public foster care adoption is traceable to the ASFA of 1997 in which the "best interest of the child" is to be achieved by terminating parental rights within mandated time frames to speed the process of adoption, authorizing financial incentives to states, to increase the number of completed adoptions, and encouraging "concurrent" or sequential planning, a process whereby adoption placement workers work toward reunification while at the same time establishing a contingency plan (Evan B. Donaldson Adoption Institute, 2002; Fisher, 2003; Schene, 2001; Zamostny, O'Brien, Baden, \& O'Leary Wiley, 2003). Others point out that the growth in public adoption began well in advance of ASFA (Cole \& Donely, 1990). In fact, the number of completed adoptions nearly doubled from about 25,000 in 1995 to about 47,000 in 1999 (Wulczyn \& Hislop, 2002). No matter on which side of the debate one stands, the fact remains that a greater proportion of children under state care are being placed into permanent family relationships than ever before.

The National Adoption and Foster Care Analysis and Reporting System offers a more detailed analysis of foster care activity and characteristics of triad members than previously available. Findings from the most recent 5 years (1999-2003) of continuous data collection and reporting offer a closer glimpse of this population. The number of eligible, cleared children "waiting" for adoption remained well over 100,000 nationally from 1999 to 2000 (U.S. Department of Health and Human Services, 2005). Of the 567,000 children in active foster care in 1999, 131,000 (23\%) were waiting and eligible to be adopted. By 2003, the number of active foster care children had dropped to 523,000, but those on the waiting list still accounted for about $23 \%(118,000)$ of all children in the public foster care system. Over this same 5-year period, the percentage of children adopted from the waiting lists was $36 \%$ in 1999 (47,000 of $131,000)$ and $42 \%$ in 2003 (49,000 of 118,000). Conversely, about one half of the children eligible for adoption at the end of fiscal year 2003 remained without a permanent home.

Boys and girls are equally likely to be adopted from foster care. Gender parity tends to also hold in public adoption cases but not in international adoption, as females account for $63 \%$ of all out-of-country adoptions. Of the 297,000 children who entered foster care in $2003,46 \%$ were White, $27 \%$ Black, and 17\% Hispanic. A majority of children (47\%) adopted from foster care were very young, ranging in age from 1 to 5 ; another $30 \%$ were ages 6 to 10 . The average age was 7 . In terms of the relationship of the adoptive parents to the child prior to the adoption, a majority of children adopted from the state welfare system in 2003 went home to foster parents $(62 \%)$ a relative $(23 \%)$, or a nonrelative $(15 \%)$.

\section{International Adoption}

At any given moment, an estimated 100 million children located around the world have no available caregivers (Child Welfare League, 2003). A joint report by the United Nations and United Nations International Children's Emergency Fund (now United Nations Children's Fund) (2002) estimates that the numbers of children with no parental care may be as high as 65 million in Asia, followed by Africa (34 million) and Latin America and the Caribbean ( 8 million). The causes are many, but a majority of these children are the product of civil war, overpopulation, famine, poverty, abandonment, or as is the case in China, a devaluation of girls. The United States remains, by far, the primary receiving nation of orphaned children, followed distantly by other Western nations, including France, Canada, and Germany. Of the 40,000 or more international adoptions that are estimated to have taken place worldwide in 2004 , more than one half $(N=22,884)$ were adopted by U.S. families (U.S. Department of State, 2005). Pertman (2000) points out that given the fact that the United States is a nation of immigrants, “it's not an accident that Americans adopt more children than do the inhabitants of the rest of the planet combined" (p. 68).

Over the past quarter century, there has been a surge in international adoptions by American families. Available data demonstrate that a total of 174,395 foreign children were adopted 
between 1994 and 2004, a 175\% increase in just one decade, as verified by immigrant visa records maintained by the U.S. Department of State (2005). Figure 3.4 offers a histogram demonstrating the significant growth in international adoption activity. Going back to 1989 figures, 8,102 international orphan visas were issued compared with 22,884 in 2004. With respect to the gender of the child, a majority of international children adopted into the United States are female (e.g., 63\% in 2001); clearly, this is a direct result of the fact that nearly all the children adopted from Mainland China, the largest of the sending nations, is female. For the remaining nations of origin, the gender disparity is nonexistent (CWLA, 2003).

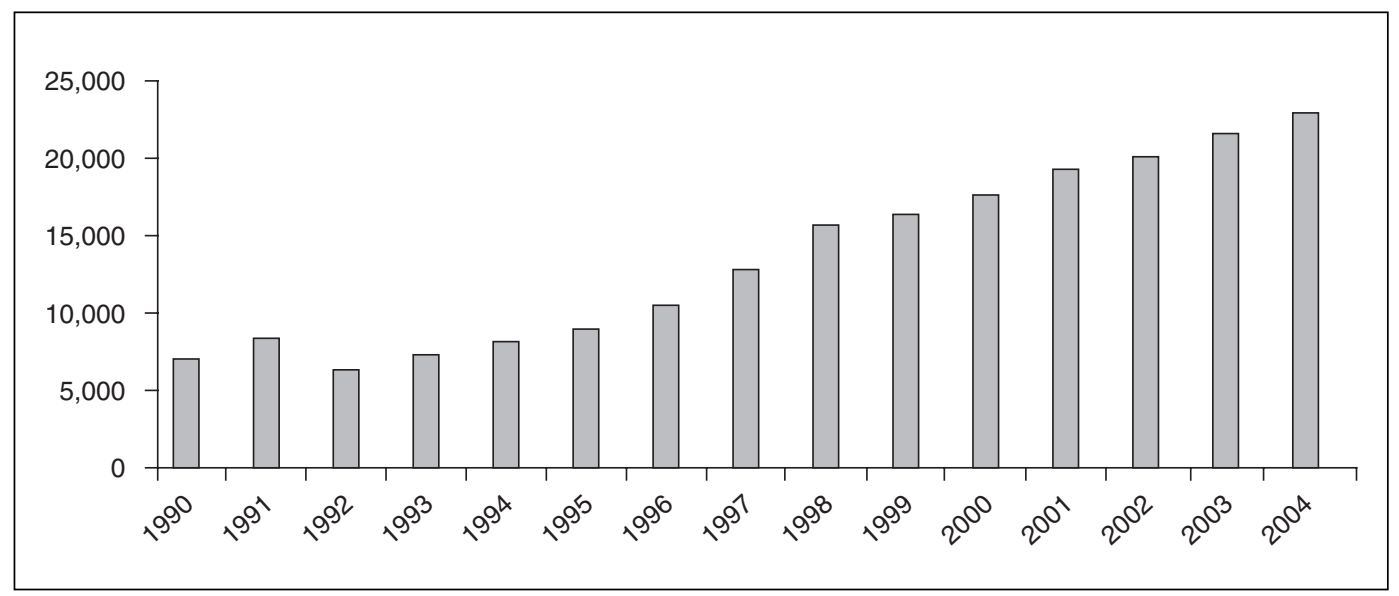

Figure 3.4 International Adoption (1990-2004): Immigrant Visas Issued to Orphans SOURCE: U.S. Department of State (2005).

The ordering of the 10 most common sending nations changes rather frequently. This is typically in direct relation to the political climate of the time, for example, reflecting nationalism and pride as much as anything else, argues Pertman (2000), which in turn spills over into wavering adoption policies. The Department of State maintains an up-to-date Web site, where interested parties can turn to determine the specific adoption policies of each sender nation. Here is but one example in just a 10-year period (1994-2004):

\begin{tabular}{|c|c|c|c|c|}
\hline \multirow[b]{2}{*}{ No. } & \multicolumn{2}{|c|}{1994} & \multicolumn{2}{|c|}{2004} \\
\hline & Country & Visas Issued & Country & Visas Issued \\
\hline 1. & South Korea & 1,795 & Mainland China & 7,044 \\
\hline 2. & Russia & 1,530 & Russia & 5,865 \\
\hline 3. & China & 787 & Guatemala & 3,264 \\
\hline 4. & Paraguay & 483 & South Korea & 1,716 \\
\hline 5. & Guatemala & 436 & Kazakhstan & 826 \\
\hline 6. & India & 412 & Ukraine & 723 \\
\hline 7. & Colombia & 351 & India & 406 \\
\hline 8. & Philippines & 314 & Haiti & 356 \\
\hline 9. & Vietnam & 220 & Ethiopia & 289 \\
\hline 10. & Romania & 199 & Colombia & 287 \\
\hline
\end{tabular}

International adoption is viewed often as a first choice among middle-class working adults, over natural childbirth or domestic adoption. One important and obvious observation in modern patterns is that American families are actively seeking to adopt children 
who are racially and culturally different from themselves. The rise in international adoption seeking may also be correlated with the strong possibility of locating and adopting an infant. In 2001 , only $2 \%$ of the children adopted from the public welfare system were less than 1 year of age, whereas $44 \%$ of all internationally adopted children were less than 1 year. Another reason for the recent momentum may be traced to more humanitarian reasons, a sense of obligation to support children in the aftermath of the U.S.-led military involvement in South-east Asia, that is, Korea and Vietnam. Powerful images of orphaned and abandoned children were brought into the homes of mainstream America in the form of evening news, daily papers, and weekly magazines. Moving images of Operation Babylift during the Vietnam War in 1975 left not only indelible images but also dreams in the minds of many for the first time of adopting and raising an international child. International alliances and shared policy documents have also continued to take shape and lay a framework for international cooperation. Some of the most important have included the 1957 International Conference on Intercountry Adoptions, the 1959 United Nations Assembly Declaration of the Rights of the Child, the 1961 Immigration and Nationality Act, and the 1999 Hague Convention.

While many adoption experts see the positive sides of internationalization, some researchers have described the challenging conditions confronted by a growing number of international orphans, particularly those who are a bit older and have spent long periods of time in decaying institutions and who have been exposed to adverse conditions. In a recent report published by the Institute of Child Development at the University of Minnesota, Gunnar, Bruce, and Grotevant (2000) call for greater awareness and research that will help families and policymakers better understand the physical, cognitive, and behavioral consequences of maternal deprivation, malnutrition, starvation, stimulus privation, and unsanitary conditions in institutionalized settings. While many children are incredibly resilient and demonstrate remarkable recovery and growth after adoption, oftentimes, as these authors note, the problems are so serious that they can easily overwhelm the adoptive families mentally and financially. Too often, children's records in the nation of origin are unavailable, incorrect, or falsified (Gunnar et al., 2000).

In reaction to the growing demand for international babies, a number of adoption service organizations and private attorneys have emerged to offer specialized services for prospective parents. While many of these have been motivated principally by compassion and altruism, one adoption expert cautions us that a growing number have joined the business to make a quick buck from "the misery of destitute children and infertile adults" (Pertman, 2000, p. 74). Adoptive parents are coming together in greater numbers and sharing critical information in parent support groups as well as staying connected and informed through digital networks. To be certain, the computer, Internet technology, and dedicated software packages have radically altered many aspects of the adoption process, from exposing could-be parents to photos of available children as close as their nearest state-run foster care agency to as far away as China, India, and member nations of the former Soviet Union. Additionally, in terms of tracking adoption data, recent advances in electronic data entry and database technology offer the potential for adoption experts to stay on top of statistical trends as they unfold. Ultimately, adoption statistics are only as reliable as the source of data itself. As the saying goes, among statisticians when referring to the reliability of data sources, "garbage in, garbage out." We are encouraged by the possibility that in the years to come, footnotes describing the cautions of missing and estimated data will no longer be necessary.

\section{REFLECTION QUESTIONS}

1. What are the strengths and weaknesses of the three primary sources of adoption statistics available today-NCSC, AFCARS, and population surveys? 
2. Of the three most common sources of adoption data-that is, public foster care, international adoption, and domestic private adoption, the least reliable and least valid in terms of statistics remains domestic private adoption. Why is this?

3. How do random population surveys further our understanding of adoption?

\section{REFERENCES}

Child Welfare League of America. (2003). International adoption: Trends and issues. CWLA November Issue Briefs. Retrieved August 11, 2006, from http://ndas.cwla.org

Child Welfare League of America. (2005). Adoption fact sheet. Retrieved January 15, 2006, from http://cwla.org/programs/adoption/adoptionfactsheet.htm

Cole, E., \& Donely, K. (1990). History, values and placement policy issues. In D. Brodzinsky \& M. Schechter (Eds.), The psychology of adoption (pp. 273-294). New York: Oxford University Press.

Evan B. Donaldson Adoption Institute. (2002). Fact overview. Retrieved January 15, 2006, from www.adoptioninstitute.org/factoverview.html

Fisher, A. (2003). Still not quite as good as having your own? Toward a sociology of adoption. Annual Review of Sociology, 29, 335-360.

Flango, V. (1990). Agency and private adoptions, by state. Child Welfare, 69(3), 263-275.

Flango, E., \& Flango, C. (1995). How many children were adopted in 1992? Child Welfare, 74, 1018-1032.

Gunnar, M., Bruce, J., \& Grotevant, H. (2000). International adoption of institutionally reared children: Research and policy. Development and Psychopathology, 12, 677-693.

Hill, R. (1977). Informal adoption among black families. Washington, DC: National Urban League.

Kreider, R. (2003). Adopted children and stepchildren, 2000. Census 2000, special reports. Washington, DC: U.S. Bureau of Census.

Lenzini, L., \& Russo, G. (2004). Family ties. Special report published by the Children and Family Research Center at the School of Social Work, University of Illinois at Urbana, Champaign. Retrieved January 15, 2006, from www.fosteringresults.org

Maza, P. (1984). Adoption trends: 1944-1975. Child welfare research notes, No. 9. Washington, DC: Administration for Children, Youth and Families.

Maza, P. (2000). Using administrative data to reward agency performance: The case of the federal adoption incentive program. Child Welfare, 79(5), 444-456.

McFarland, M. (2003). Adoption trends in 2003: A deficiency of information. National Center for State Courts Documents. Retrieved August 11, 2006, from www.ncsconline.org/WC/Publications/KIS_ Adopt_Trends03.pdf

Pertman, A. (2000). Adoption nation: How the adoption revolution is transforming America. New York: Basic Books.

Schene, P. (2001). Implementing concurrent planning. In B. Sparks (Ed.), A handbook for child welfare administrators. National Child Welfare Resource Center, University of Southern Maine, Portland.

Stolley, K. (1993). Statistics on adoption in the United States. The Future of Children, 3(1), $26-42$.

Testa, M., \& Falconnier, K. (1998). Improving data collection on adoption and relinquishment of children in the National Survey of Family Growth. Chicago: School of Social Service Administration (Report to the Centers for Disease Control and Prevention, U.S. Department of Health and Human Services).

United Nations Children's Fund. (2002). Children on the brink 2002: A joint report on orphan estimates and program strategies from USAID, UNICEF and UNAIDS. Washington, DC: TvT Associates. Retrieved January 15, 2006, from www.dec.org/pdf_docs/PNACP860.pdf 
U.S. Department of Health and Human Services. (2004). How many children were adopted in 2000 and 2001? Washington, DC: National Adoption Information Clearinghouse.

U.S. Department of Health and Human Services. (2005). AFSCARS report No. 10. Retrieved May 1, 2006, from www.acf.hhs.gov/programs/cb

U.S. Department of State. (2005). Immigrant visas issued to orphans coming the the U.S.: Top countries of origin. Retrieved January 7, 2006, from http://travel.state.gov/family/adoption/stats/ stats_451.html

U.S. House of Representatives, Committee on Ways and Means. (2004). Title IV Adoption Assistance Program (available in the 2004 Green Book). Washington, DC: Government Printing Office.

Wulczyn, F., \& Hislop, K. (2002). Growth in adoption population. University of Chicago, Chapin Hall Center for Children, Discussion Papers. Retrieved April 5, 2006, from http://aspe.hhs.gov/ hsp/fostercare-issues02/adoption/index.htm

Zamostny, K. P., O’Brien, K. M., Baden, A. L., \& Wiley, M. O. (2003). The practice of adoption history, trends, and social context. The Counseling Psychologist, 31(6), 651-678. 